\title{
Unsafe Abortion: an Inequity in Health Care, Thailand Perspective
}

\author{
Kamheang Chaturachinda ${ }^{1}$ and Nongluk Boonthai ${ }^{1}$
}

\begin{abstract}
"Women are not dying of diseases we cannot treat, they are dying because societies have yet to make the decision that their lives are worth saving" (Fathalla, 2006).

"The underlying cause of morbidity and mortality from unsafe abortion today are not blood loss and infection but rather apathy and disdain toward women" (Grimes et al., 2006).
\end{abstract}

Each year worldwide up to 68,000 women die due to unsafe abortion. Many thousands more are maimed for life from complications of unsafe abortion. In Thailand, up to 10-15 percent of maternal deaths are due to unsafe abortion. Many thousands of women are still hospitalized because of this preventable pandemic. The National Health Security Office had spent 150 million Baht of the annual health care budget on treating complications arising from unsafe abortion.

Unsafe abortion is the termination of unintended or unwanted pregnancy by an unskilled individual without the necessary skill or conducted in a place that does not meet minimum medical standards. Among the factors that can lead to unsafe abortion are socio-economic, politic, religion and belief, legal, health care system, health care provider, and technology.

The main barrier to the access of safe abortion service in Thailand is the negative attitude towards abortion on the part of health care providers. To rectify this there has to be a paradigm change in society and among health care providers.

Keywords: maternal death, unsafe abortion, women's health, inequity, manual vacuum aspirator, medical abortion

Women's Health and Reproductive Rights Foundation of Thailand Email:gumhang@hotmail.com 


\section{Introduction}

Worldwide 47,000 women die from complications resulting from unsafe abortion each year. Deaths due to unsafe abortion remain close to 13 percent of all maternal deaths (WHO, 2011). In Thailand, diseases arising from unsafe abortion include death and long term debility among women, not to mention the expenses involved in dealing with complications arising from unsafe abortion (Phuapradit et al., 1985; Chaturachinda, 2014). The specific mortality ratio for unsafe abortion is 300 times more than that of safe abortion (Worakamin et al., 2004). This has gone on for many years in the past. The reason for this is due to inequity of health care for women in Thailand.

The discovery of 2002 fetal remains in 3 temples in Bangkok in 2006 made worldwide headlines, plus daily reports of abandoned new born babies and reports of infanticide in the vernacular press reflects the plight of women with unintended pregnancy and their inability to gain access to safe medical care (Chaturachinda, 2014). Thailand has been complimented for its success in family planning for achieving contraceptive prevalence of over 75 percent and reducing the total fertility rate from 5.4 in 1960's to 1.2 in 2010. Despite this women in Thailand are still dying and being maimed from complications arising from unsafe abortion.

\section{Unsafe Abortion}

Unsafe abortion is defined as termination of unintended or unwanted pregnancy either by an individual without the necessary skills or where undertaken in an environment which does not conform to minimum medical standards or both (WHO, 2006).

\section{Determinants of Unsafe Abortion}

Determinants of unsafe abortion are diverse ranging from proximate and systemic factors. Proximate factors relate directly to a women's fertility behavior such as contraceptive choice and practice and are the factors that can cause unintended pregnancy. Unwanted pregnancy can occur for numerous reasons; from non-use of contraception, contraceptive failure, its improper use, and sexual violence. The proportion of unwanted pregnancy that ended in abortion has been estimated at 58 
percent worldwide (Guttmacher, 1999), and much higher for Thailand (WHO, 2012).

Systemic determinants are the factors that determine the conditions leading to safe or an unsafe abortion (Table 1). By and large, women in developing world like Thailand are prevented from exercising their reproductive rights, unlike their counterparts in the developed world. The systemic factors include service factors, social factors, economic factors, religious factors, and policy or political factors.

Table 1: Diagram of Determinants of Unsafe Abortion

\begin{tabular}{|l|l|}
\hline \multicolumn{1}{|c|}{ Proximate Factors } & \multicolumn{1}{|l|}{ Systemic factors } \\
\hline - Factors relate to reproductive behavior & $\bullet$ Service \\
- Use and non-use of contraception & $\bullet$ Social \\
- Sexual violence / rape & - Economic \\
& $\bullet$ Religious \\
& - Policy \\
& - Law \\
\hline
\end{tabular}

\section{Socio-Economic Factors}

Education and level of income plays an important part with regards to access to health service. Poorly educated and low income earners are often excluded from health care service because they are ignorant of their rights, laws and other barrier. Restricted laws are often barrier to safe abortion service. In Thailand, women still cannot gain access to safe abortion due to a lack of information, violation of their rights as well as social stigma (Berer, 2000)

\section{Stigma}

Thai society regards abortion as immoral and sinful (Whittaker, 2004). Stigma related to abortion particularly affects adolescents and unmarried women. Social sanction against sexual activities in teenagers and unmarried are social norm in Thailand (Whittaker, 2004).

This stigmatization on the part of health care providers leads to denying safe abortion to women who needed it (Chaturachinda, 2011). Stigma can be challenged and overcome by education (Campbell et al., 2005; Campbell \& Deacon, 2006) and the 
sooner it is eliminated the better for women's reproductive health in Thailand (Harris, 2008; O’Donnell et al., 2011; Cook, 2014).

\section{Law}

Law is an important determinant of safe abortion. Restricted law block access to safe abortion (Cook, 2016). Even though Thai penal code Article 305 and Thai Medical Council Regulation BE 2548 permits abortion to be carried out by physicians, women in Thailand cannot access safe abortion services due to lack of information and the perception that abortion is illegal in Thailand (Whittaker, 2004). Change in abortion law has been demonstrated to reduce maternal mortality and morbidity from abortion in United Kingdom and Nepal (Bpas, 2014; Upreti, 2014).

Decriminalization of abortion does not increase the number of abortion. This is seen in Canada where there was no abortion law since 1988 when the supreme court of Canada struck down the old colonial abortion law as being in violation of women's rights (Canada Abortion Laws, 2016).

\section{Policy}

Politics has an important role in access to abortion services (Whittaker, 2002). No politician in Thailand wants to risk political careers by publicly supporting measures to liberalize abortion policy (Whittaker, 2004).

Politics also played a major role in access to safe abortion service (Mundigo, 2006). In Thailand, almost all political parties are ambivalent toward abortion issue. Some political party (such as now defunct "Palangdhama Party") is known to be an ardent anti-abortion party, regarding abortion as immoral and sinful. The Secretary General of this political party restricted the use of misoprostol, a medication used in treatment of gastric ulcer, and used 'off label' to induce abortion, that then could be obtained over the counter for less than baht 10 per tablet prior to 2002 when she became the Minister of Public Health in 2002. Consequence to this ban the cost of this medication rocketed to up to baht 5,000 per tablet. It is strictly available by prescription and in hospital use only. 
International politics also dictates access to abortion care (Crane \& Dusenberry, 2004). The election of a Republican US President in November 2016 has led to the Global Gag rule of President Reagan's era to be reinstituted.

\section{Service Factors}

\section{Health Care System}

Health care systems play an important role in the provision of safe abortion services. Historically the Thai National Health Security Office (NHSO) began in 2002 as the health organization providing free health care for Thai citizens possessing 13-digit identification number from the time of birth to point of death (similar to the National Health Service in United Kingdom). The NHSO is allocated an annual budget from the national budget on a per capita basis (the allocation for the year 2017 is 3,218 Baht per capita). Its mandate is to buy as well as ensure quality health care service in government and privately owned hospitals (NHSO, 2017). NHSO provides medication for medical abortion as well as surgical procedure free of charge for women requiring safe abortion.

\section{Abortion and Human Rights}

Abortion is a major public health concern and denial of access to safe abortion service is regarded as violation of Human Rights (Cook, 2006; Dehlendorf et al., 2013). International organizations increasingly regard the denial of safe abortion services as a human rights violation (UN Committee on the Elimination of Discrimination against Women, 2017). Thailand has passed a law against discrimination of sexes in 2015. So far no women or human rights organization in Thailand has legally challenged any public hospital for refusing to provide safe abortion service.

\section{Abortion Technology}

\section{Surgical Abortion}

Abortion technology has advanced by leaps and bounds in the last three decades. The use of vacuum to empty the uterine content has improved since it was first 
introduced in 1960's (Kerslake \& Casey, 1967). It is safer to use than the traditional dilatation and curettage. This simple technology relies on the use of a simple $60 \mathrm{cc}$ syringe with a plunger to generate negative pressure for uterine evacuation and plastic cannulas of various sizes. The negative pressure generated by this simple syringe is similar to that generated by a large, expensive pump used in the hospital operating room.

Figure 1: A Manual Cacuum Aspiration Device, $60 \mathrm{cc}$. Syringe for Uterine Aspiration

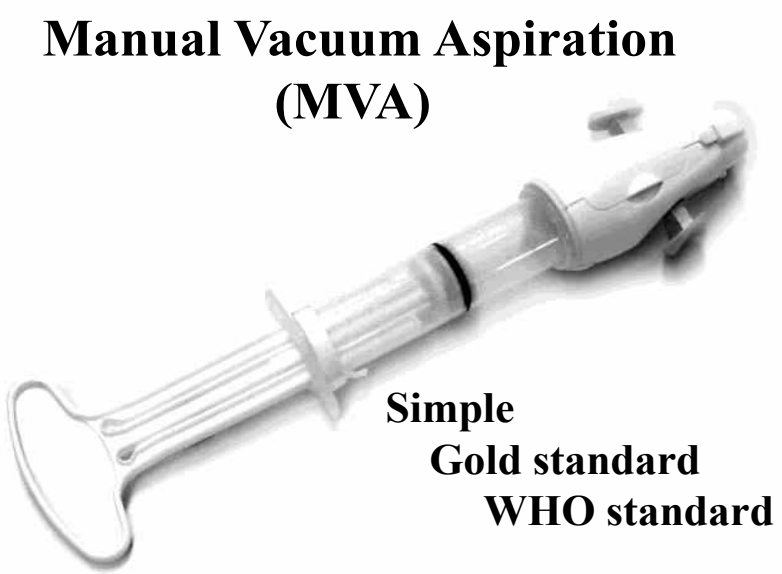

This manual vacuum aspirator (MVA) is recommended by WHO as a safe method of uterine evacuation than the traditional dilatation and curettage. It can be cleaned, high-level disinfected or sterilized and re-used many times. Similarly, the cannulas can also be sterilized and reuse repeatedly (WHO, 2012). Yet Thai physicians are not using this simple, safe and effective instrument for evacuation of uterine contents (Suphanchaimat et al., 2013).

MVA can be used to terminate pregnancy safely at primary care level by mid-level health personnel such as trained nurses and midwives (WHO, 2015; WHO, 2016).

\section{Medical Abortion}

A combination of an anti-progesterone drug $200 \mathrm{mg}$ of Mifepristone and a prostaglandins derivative, $200 \mathrm{mg}$ of Misoprostol, is a powerful drug for termination of pregnancy (Gemsell-Danielsson et al., 2016). Mifepristone acts by blocking the uptake of progesterone, the hormone needed for continuation of pregnancy, 
produced by the ovary. While Misoprostol contracts the uterus thus expelling the dead embryo - the process is very similar to an early miscarriage. (IPPF, 2008; IPPF, 2017)

The procedure is very safe and effective. The success rate in early pregnancy is reported at $95-98 \%$. Research on home medication is ongoing; and early results suggest that it is safe to take it at home (WHO, 2016).

\section{Health Care Providers}

Health care providers play a decisive role in terms of access to safe abortion service and which may be denied to women if health care providers continue to have a negative attitude towards abortion (Praditpan, 2016). This is the main reason why women in Thailand cannot gain access to safe abortion. Changing attitude of health care providers would go a long way towards alleviation of the inequity in health care (Arisi, 2003).

\section{Where Do We Go from Here?}

\section{Short Term}

Ideally preventing an unintended pregnancy is the best. Information on prevention of unintended pregnancy and contraceptive service should be provided to women of reproductive age including teen ages and adolescents. It is well recognized that there is no perfect contraception other than total abstinence from sexual activity (WHO, 2015). When pregnancy occurs following either from not using or the failure of contraception, interruption of early pregnancy is safe and cost effective (WHO, 2016).

Safe abortion advocacy and training of health care providers is urgently needed. Increasing the availability of abortion drugs would also improve access to this essential reproductive health service and incidentally reduce the inequity of sexes in health care service. 


\section{Long Term}

The public needs to be educated on women's rights to equitable health care service including safe abortion service. Abortion should not be seen as a crime, the learning process should include, though not exclusively, topics or discussions concerning women's health and women's rights, stigma-discrimination, socio-economic and health burden of disease of unsafe abortion, determinants of unsafe abortion, history of abortion laws worldwide and Thailand, professionalism and duty of health care providers, modern abortion technology, modern contraception, as well as practical aspects of reproductive health care. In addition, the importance of patient's primacy, patient's safety, patient autonomy should be taken into consideration.

Empowering women to demand a woman's right to save their own life and choose to continue or terminate their pregnancy is vital. (Lancet, 2007; Grimes et al., 2006).

Finally, decriminalization of abortion would benefit women's health and prevent maternal mortality and morbidity in a society that fails to realize that "women's lives are worth saving" (Fathalla, 2006) and eliminating the "apathy and disdain toward women". (Grimes, 2006).

\section{References}

Arisi, E. (2003). Changing attitudes towards abortion in Europe. Eur $j$ Contracept Reproductive Health Care, 8(2), 109-21.

Arthur, J. (2014). Commentary: Why the UK does not need an abortion law at all: Abortion review. Bpas publication London.

Berer, M. (2000): Making abortions safe: a matter of good public health policy and practice. Bull World Health Organization, 78, 580-592.

Boonthai, N., Tantives, S., Tangchareonsathien, V., \& Chaturachinda K., (2010). Improving access to safe termination of pregnancy in Thailand: An analysis in policy development from 1999-2006. In Abortion in Asia Local Dilemma, Global politics. Ed Whittaker A: Publisher Berghahn Books.

Bpas. (2014). Abortion Law Reformers Pioneers of change. Bpas publication London. Canada abortion law (2008). Abortion Laws Around the World. Retrieved from http://www.nafcanada.org/legal-abortion-ca.html 
Chaturachinda, K. (2011). Unsafe abortion still a thorn in reproductive life of women in Thailand: in Chatchaval Memorial Oration. RTCOG congress book, 1-6.

Chaturachinda, K. (2014). Unsafe abortion in Thailand: Roles of RTCOG. Thai Journal of Obstetrics and Gyanecology, 22, 2-7.

Chaturachinda, K. (2016). The role of RTCOG in prevention of maternal mortality and morbidity from unsafe abortion in Thailand: in Luang Waithayesrangul Memerial Oration, RTCOG Congress Book, 67-76.

Crane, B. B., \& Dusenberry, J. (2004). Power and politics in International funding for reproductive health: the US Global Gag Rule. Reproductive Health Matters, $12,128-137$.

Campbell, C., Foulis, C. A., Maimane, S., \& Sibiya, Z. (2005). I have an evil child at my house: stigma and HIV/AIDS management in a South African community, American Journal of Public Health, 95(5), 808-15. DOI: 10.2105/AJPH.2003.037499

Campbell, C., \& Deacon, H. (2006). Unraveling the contexts of stigma: From internalisation to resistance to change, Journal of Community \& Applied Social Psychology, 16(6), 411-417. DOI: 10.1002/casp.901

Cook, R. J. (2006). Abortion, human rights and the international Conference on Population and Development (ICPD), Guttmacher Institute, 15-34.

(2006) Preventing Unsafe Abortion and Its Consequences: Priorities for Research and Action, Guttmacher Institute, 15-33.

Cook, R. J. (2014). Stigmatized Meaning of Criminal Abortion law.in Abortion law in Transnational Perspective: Cases and Controversies, University of Pennsylvania Press, 347-369.

Dehlendorf, C., Harris, L. H., \& Weitz, T. A. (2013). Disparities in abortion rates: a public health approach. Am J Public Health, 103, 1772-1779.

Fathalla, M. F. (2006). Human rights aspect of safe motherhood. Best Pract Res ClinObstet Gynaecol, 20, 409-19.

Gemzell-Danielsson, C., Fiala, C., Agostini, A., Cameron, S., Bombas, T., Lertxundi, R. \& Parachini, M. (2016). Medical Abortion beyond the $1^{\text {st }}$ trimester including fetal death in utero: A practical guide for health care professionals, Exelgyn.

Grimes, D. A., Benson, J., Singh, S., Romero, M., Ganatra, B., Okonofua, F. E. \& Shah, I. H. (2006). Unsafe abortion: the preventable pandemic, Lancet, 368, 1908-1919.

Guttmacher institute. (1999). Sharing Responsibility: society, and Abortion Worldwide. Guttmacher Institute. 
Harris, L. (2008). Second trimester abortion provision: Breaking the silence and changing the discourse. Reproductive Health Matters. 16(31), 74-81. DOI: $10.1016 / \mathrm{S} 0968-8080(08)$

31396-2

International Planned Parenthood Federation. (2008). Access to safe abortion; a tool for assessing legal and other obstacles. International Planned Parenthood Federation.

International Planned Parenthood Federation. (2017). The Abortion pill at a glance. International Planned Parenthood Federation. Retrieved January 12, 2017 from Website: https://www.plannedparenthood.org/learn/abortion/theabortion-pill\#sthash.fL6s5Z1Z.dpuf

Iyengar, K., \& Iyengar, S.D. (2002). Elective abortion as a primary health service in rural India: experience with manual vacuum aspiration, Reproductive Health Matters, 10, 54-63.

Kerslake, D., \& Casey, D. (1967). Abortion induced by means of the uterine aspirator. Obstet Gynecol, 30(1), 35-45.

Lancet (2007). Women: more than mothers, Lancet, 370:9595, 1283-1284. DOI: 10.1016/S-0140-6736(07)61546-3

Mundigo, A.I. (2006). Determinants of unsafe induced abortion in developing countries, Guttmacher Institute, 51-71.

O'Donnell, J., Weitz, T., \& Freedman, L. (2011). Resistance and vulnerability to stigmatization in abortion work. Social Science and Medicine, 73(9), 13571364. DOI: 10.1016/j.socscimed.2011.08.019.

Phuapradit, W., Siriwongs, B., \& Chaturachinda. K. (1985) Maternal Mortality in Ramathibodi Hospital: a 14-year review. Journal of Medical Association of Thailand, 68(12), 654-658.

Praditpan, P., Chaturachinda, K. (2016, January 29) Doctors must heed abortion needs. Bangkok Post, pp. 10.

United Nations committee on the elimination of discrimination against women. General recommendation 24: women and health (20th session), paragraph 31(c). Retrieved January 20, 2017 from

http//www.un.org/womenwatch/daw/cedaw/recommendations/recomm.htm

NHSO. Retrieved January 20, 2017 from

http://www.nhso.go.th/eng/Site/ContentItems.aspx? type=MQ==).

Suphanchaimat, R., Boonthai, N., Tangthasana, S., Putthasri, W., Tangchareonsathien, V., Chaturachinda, K. (2013) A survey of manual vacuum aspiration's experiences among the new medical graduates in Thailand. Reproductive Health. DOI: 10.1186/1742-4755-10-49 
Thailand law against discrimination of sexes. Retrieved February 12, 2017 from http://www.ratchakitcha.soc.go.th/data/pdf/2558/a/018/17.pdf

United Nations committee on the elimination of discrimination against women.

General recommendation 24: women and health (20th session), paragraph31(c). Retrieved January 20, 2017 from

$\mathrm{http} /$ www.un.org/womenwatch/daw/cedaw/recommendations/recomm.htm \#recom 24

Upreti, M. (2014). Towards Transformative Equality in Nepal: The Lakshmi Dhikta Decision: In Abortion law in Transnational Perspective; cases and controversies, University of Pennsylvania Press, 279-300.

Warakamin, S., Boonthai, N., \& Tangcharoensathien, V. (2004). Induced abortion in Thailand: current situation in public hospitals and legal perspectives, Reproductive Health Matters, 24, 147-156.

Whittaker, A. (2004). Abortion, sin and the state in Thailand. New York: Routledge Curzon

Whittaker, A. (2002). The struggle for abortion law reform in Thailand. Reproductive Health Matters, 10, 45-53.

World Health Organization (WHO) (2011). Unsafe abortion: global and regional estimates of the incidence of unsafe abortion and associated mortality in 2008. Geneva: World Health Organization.

World Health Organization (WHO) (2012). Safe abortion technical and policy guidance for health system. Geneva: World Health Organization.

World Health Organization (WHO) (2015). Health worker roles in providing safe abortion care and post-abortion contraception. Geneva: World Health Organization.

World Health Organization (WHO) (2016). Expanding health worker roles for safe abortion in the first trimester of pregnancy. Geneva: World Health Organization. 